one of the four WAT trials $61 \%$ of the time, the probability of occurrence of an IA did not vary monotonically as a function of trial number ( .33 for the first trial to .29 for the second trial, with intermediate values on the third and fourth trials).

Within-Ss Analysis (Across-Words) WAT Data

In order to determine the response pattern of the individual Ss, a number of indices were used. The mean number of $P_{s}$ given to the 272 stimuli on the WAT was 95.8 (range $=31-150$ ). The mean number of stimulus words on the WAT for which a $P$ was given in at least one of the four WAT trials was 33.6 (range $=16-44$ ). The mean number of DRs on the WAT was 136.8 (range $=77-228$ )

Retest Data

The mean number of Ps on the retest was 27 (range $=8-40)$. The mean number of IAs that occurred on the first WAT trial and on the retest was 30.5 (range $=14-47$ ). The mean number of stimuli to which the same response occurred on any of the four WAT trials as well as the retest was 41.4 (range $=27-54$ ).

In the absence of instructions to the contrary, some Ss adopted the strategy of repeating the same response to two or more of the four presentations of a given stimulus in the WAT. The mean number of IAs in at least two trials of the WAT as well as the retest was 33.8 (range $=14-51$ ). The mean number of IAs in at least three trials of the WAT and on the retest was 26.7 (range $=4-46$ ). The mean number of IAs given on all four trials of the WAT and on the retest was 18.2 (range $=0-44$ ). If $S$ adopted the strategy of giving the same response to each word on the four trials of the WAT as well as the retest he would have had 272 IAs. In the present sample, the mean number of IAs was 118.4 (range = 49-196).

Those Ss who tended to emit Ps tended to repeat their response or adopt what Applebaum (1960) has called a "reproductive" strategy. The correlation between number of Ps on the WAT and the tendency to give IAs on two or more WAT trials was highly reliable $(\mathrm{r}=.77, \mathrm{df}=70, \mathrm{p}<.01)$. The product moment correlation between the total number of Ps on the WAT and the production of IAs on all four trials of the WAT was $.75(\mathrm{df}=70, \mathrm{p}<.01)$. The correlation between number of Ps on the retest and the tendency to give an IA on all four trials of the WAT was $.60(\mathrm{df}=70$, $\mathrm{p}<.01$ ). Those $\mathrm{Ss}$ who tended to give a large proportion of Ps and IAs gave few DRs. For example, there was a strong negative correlation $(r=-.72)$ between DR and total number of Ps on the WAT. Moreover, there was a strong negative correlation $(r=-.67)$ between DR and number of IAs on the first WAT trial and the retest.

Although there was little difference in either the number of Ps or the number of IAs given on the four trials of the WAT, there were significantly more Ps given to the stimuli on the retest than on any of the four WAT trials. Using a $t$ test for correlated measures, there was a significant difference between the number of Ps on the first WAT trial (36.3\%) and the number of Ps given in the retest $(39.5 \%)[t(67)=2.90, p<.01]$. This finding was in accord with the data reported by Weintraub, Silverstein, \& Klee (1960) whose normal Ss, displaying what was called "corrective" behavior, gave significantly fewer populars in a WAT than in a re test administered 1 week later.

\section{GENERAL COMMENTS}

The present study, while replicating the results of earlier research which demonstrated a strong relationship between DP and TRR (Brotsky \& Linton, 1967b, c), failed to produce a hierarchy of four discrete responses from each of the Ss to each of the 68 words. This was due to the pronounced tendency on the part of Ss to emit the same response to two or more presentations of a given stimulus. This strategy was related both to the shape of the normative response hierarchy of the stimuli and Ss' tendency to respond with Ps. Thus, in the absence of contrary instructions, those Ss who tended to give a large number of Ps (popular responders) tended to emit the same $P$ at the intervals ranging from minutes to days or weeks. When a stimulus had no highly dominant $P$, there were many competing DRs, and reproduction occurred less frequently. Even those $S s$ who rarely gave Ps (idiosyncratic responders) tended to reproduce Ps when the stimulus had a very strong popular. With stimuli having weaker populars, however, the idiosyncratic responders tended not to repeat their responses, producing a low degree of TRR.

\section{REFERENCES}

APPLEBAUM, S. A. Automatic and selective processes in the word associations of brain damaged and normal subjects. Journal of Personality, 1960, 28, 64-72.

BROTSKY, S. J., BUTLER, D. C., \& LINTON, M. L. Association time, commonality, and the test-retest reliability of free association responses. Psychonomic Science, 1967, 9 319-320.

BROTSKY, S. J., \& LINTON, M. L. The San Fernando Valley State College word association norms. Technical Report No. 1, 1967a, San Fernando Valley State College, Research Grant 4.259.01, San Fernando Valley State College Foundation.

BROTSKY, S. J., \& LINTON, M. L. The test-retest reliability of free association norms. Psychonomic Science, $1967 \mathrm{~b}, 8,425426$.

BROTSKY, S. J., \& LINTON, M. L. The test-retest reliability of free associations following continued associations. Psychonomic Science, $1967 \mathrm{c}, 9,85-86$

CRAMER, P. Word association. New York: Academic Press, 1968.

THORNDIKE, E. L., \& LORGE, I. The teacher's word book of 30,000 words. New York: Teacher's College, Columbia University, 1944. WEINTRAUB, W., SILVERSTEIN, A., \& KLEE, G. D. The "correction" of deviant responses on a word association test. Archives of General Psychiatry, 1960, 3, 17-20.

\section{NOTE}

1. This research was supported in part by a research grant to the first author from the San Femando Valley State College Foundation and by a faculty research award to the second author from the San Diego State College Foundation. The report was written during the first author's tenure as NIH Special Fellow in Human Development, Harvard University.

\title{
The effect of pronunciation practice on anagram difficulty
}

ROGER L. DOMINOWSKI, University of Illinois at Chicago Circle, Chicago, Ill. 60680

A comparison was made of the solution difficulty of anagrams differing in pronounceability but having the same solutions, either with or without prior pronunciation practice with the anagrams. Anagrams rated easier to pronounce had faster promunciation speeds and lower solution probabilities. Pronunciation practice increased reading speed and reduced solution probability. It was suggested that pronounceability reflects $S s^{\prime}$ tendencies to deal with an anagram as a unit rather than as a sequence of letters, and the results were related to comparisons of word and nonsense anagrams.

Hebert \& Rogers (1966) reported that anagrams which are easy to pronounce (EP) are more difficult to solve than anagrams that are hard to pronounce (HP). However, the design of their study did not permit an unambiguous conclusion concerning the effect of anagram pronounceability since EP and HP anagrams had different solution words. Other research has indicated that individual solution words exhibit consistent differences in difficulty even when their respective anagrams are radically changed (e.g., Dominowski, 1967). Thus, it is possible that the difference between pronounceability conditions was due, to some unknown degree, to differences in solution words. A major purpose of the present study was to compare anagrams varying in pronounceability but having the same solution words. 
Attributing causal status to pronounceability is also made difficult because of the likely correlation of this characteristic with other reasonably effective attributes. Hebert and Rogers pointed to meaningfulness as a likely correlate of pronounceability. The likelihood that pronounceability is the critical feature may be increased by employing a training technique designed to change pronounceability while not affecting meaningfulness. Newman \& Williams (1967) have shown that trigrams rated as EP are pronounced more rapidly than those rated HP, and, more importantly, that reading practice reduces pronunciation times for all items. However, such practice does not change meaningfulness (Schulz \& Thysell, 1965). Therefore, repetitive reading of anagrams should increase their pronounceability (as evidenced by faster reading speeds) and, if pronounceability is a critical anagram characteristic, make them more difficult to solve. The present study involved a comparison of anagrams differing in rated pronounceability (but having the same solutions), either with or without pronunciation practice.

\section{MATERIALS}

From a list of five-letter words beginning with consonants, having Thorndike-Lorge ratings of $\mathbf{A}$ or $\mathbf{A A}$, and having no repeated letters, 20 words were selected such that letter-sequence similarity among words was low. For each word, four anagrams were constructed by employing four letter orders requiring two letter moves to reproduce the word from the anagram and containing no word letter sequences in the anagram (Dominowski, 1966). The anagrams were given to 64 introductory psychology students for pronounceability ratings, with each anagram rated by $16 \mathrm{Ss}$. The 9-point pronounceability scale ( $1=$ easy, $9=$ hard $)$ developed by Underwood \& Schulz (1960) was used.

For 5 words, the four anagrams did not differ in pronounceability. For each of the remaining 15 words, the anagrams with the highest and lowest mean ratings were selected. There were thus two lists of 15 anagrams each, with the solution words identical for the two lists. Anagrams in the EP list had mean ratings from 1.38 to 4.12 , while ratings for those in the HP list varied from 5.38 to 8.31 ; list means were 2.75 and 6.72 , respectively. The smallest difference between the EP and $\mathrm{HP}$ anagrams for a word was 2.94 units. Each anagram was typed in capital letters on an index card, and a single random order of the solution words determined the order of presentation of anagrams in both the EP and HP lists.

SUBJECTS AND PROCEDURE

There were four groups formed by the factorial combination of EP vs HP anagrams with control vs practice conditions. Forty- four introductory psychology students were individually run and were assigned to groups in alternation. In control conditions, Ss were told what an anagram is, shown an example, and then given the 15 problems to solve, with a maximum of $30 \mathrm{sec}$ allowed per problem. Solutions were given orally, and E informed $S$ of the solution whenever $S$ failed to solve a problem. In practice conditions, anagram solving was preceded by five trials of reading the list of 15 anagrams. Five different random orders of the anagrams were used, and Ss were instructed to try to pronounce each item as they would an English word if it contained those letter combinations. Within these limits, Ss were told to read the list as rapidly as possible; reading times were measured with a stopwatch. After the fifth reading trial, Ss were told that they would now be given a different task, and the instructions and procedure for the control conditions were then executed.

\section{RESULTS AND DISCUSSION}

On the first practice trial, the mean reading times for the EP and HP lists were $27.3 \mathrm{sec}$ and $50.5 \mathrm{sec}$, respectively (F $=11.69, \mathrm{df}=1,20, \mathrm{p}<.01)$. Reading time was a negatively accelerated, decreasing function of practice, with all Ss showing improvement. On the fifth trial, EP and HP lists had mean reading times of $14.2 \mathrm{sec}$ and $25.4 \mathrm{sec}$, respectively $(\mathrm{F}=10.48, \mathrm{df}=1,20$, $\mathrm{p}<.01$ ). A comparison of the means for the first and fifth trials indicated that the reduction in reading time was greater for the HP list ( $F=5.96, \mathrm{df}=1,20, \mathrm{p}<.05)$. These results are quite similar to those of Newman \& Williams (1967). Differences in rated pronounceability reflect differences in pronouncing speed, and practice improves pronunciation, with a slightly greater improvement for those items initially more difficult to pronounce.

The analysis of anagram performance was based on the number of problems solved by each $\mathrm{S}$. The mean number of solutions for EP anagrams (5.82) was significantly lower ( $F=19.89, \mathrm{df}=1,40, \mathrm{p}<.001)$ than that for HP anagrams (8.14). Pronunciation practice reduced the number of solutions, with means of 7.82 and 6.14 for control and practice conditions, respectively $(F=9.53$, $\mathrm{df}=1,40, \mathrm{p}<.01)$. The effect of practice did not interact with the initial pronounceability level of the anagrams $(F<1)$. The data were also analyzed by calculating the number of solutions for each problem, resulting in the replicate being solution words, crossed with the four conditions. The results of this analysis duplicated those presented above; furthermore, employing anagram bigram frequency (Mayzner \& Tresselt, 1959) as a covariate did not affect the results.

These findings lend considerable support to the notion that the difficulty of solving an anagram is directly related to the ease with which the anagram may be pronounced. It might be argued that pronunciation practice affects anagram difficulty by making the anagrams more familiar rather than by making them easier to pronounce. Although it may be difficult to distinguish differences in perceptual familiarity from differences in verbal encoding (see Glanzer \& Clark, 1963), this view does suggest a direction for research. If it could be shown that mere presentation or spelling practice produces minimal changes in pronunciation speed, a comparison of these types of training with pronunciation practice would be informative. Finally, as Hebert \& Rogers (1966) suggested, a consideration of pronounceability effects provides a plausible explanation for the finding that word anagrams are more difficult than nonsense anagrams (e.g., Ekstrand \& Dominowski, 1968). Words are likely to be easier to pronounce than nonsense strings and, for this reason, are better organized or more unitary stimuli which will be more difficult to rearrange. A comparison of word and nonsense anagrams equated for pronounceability would provide a test of this hypothesis.

\section{REFERENCES}

DOMINOWSKI, R. L. Anagram solving as a function of letter moves. Joumal of Verbal Learning \& Verbal Behavior, 1966, 5, 107-111. DOMINOWSKI, R. L. Anagram solving as a function of bigram rank and word frequency. Joumal of Experimental Psychology, 1967, 75, 299-306.

EKSTRAND, B. R., \& DOMINOWSKI, R. L. Solving words as anagrams: II. A clarification. Joumal of Experimental Psychology, 1968, 77, $552-558$.

GLANZER, M., \& CLARK, W. H. Accuracy of perceptual recall: An analysis of organization. Joumal of Verbal Learning \& Verbal Behavior, 1963, 1, 289-299.

HEBERT, J. A., \& ROGERS, C. A., JR. Anagram solution as a function of pronounceability and difficulty. Psychonomic Science, 1966, 4, 359-360.

MAYZNER, M. S., \& TRESSELT, M. E. Anagram solution times: A function of transition probabilities. Joumal of Psychology, 1959, 47, 117-125.

NEWMAN, S. E., \& WILLIAMS, C. M. Response speed for easy-and hard-to-pronounce trigrams. Journal of Verbal Learning \& Verbal Behavior, $1967,6,661-667$.

SCHULZ, R. W., \& THYSELL, R. The effect of familiarization on meaningfulness. Journal of Verbal Learning \& Verbal Behavior, 1965, 4, 409-413.

UNDERWOOD, B. J., \& SCHULZ, R. W. Meaningfulness and verbal learning. Chicago: Lippincott, 1960.

\section{NOTE}

1. This research was supported by a grant from the University of Illinois Research Board. Robert Horwitz assisted in data collection. 